\title{
Hemp Fiber Reinforced Polypropylene Composites: The Effects of Material Treatments
}

\author{
Theresa Sullins ${ }^{\mathrm{a}}$, Selvum Pillay*a, Alastair Komus ${ }^{\mathrm{b}}$ and Haibin Ning ${ }^{\mathrm{a}}$ \\ ${ }^{a}$ Department of Materials Science and Engineering \\ Materials Processing and Applications Development Center \\ University of Alabama at Birmingham, Birmingham, AL 35294 \\ ${ }^{\mathrm{b}}$ Composites Innovation Centre (CIC), Canada
}

\begin{abstract}
Natural fiber reinforced thermoplastic matrix composites have been increasingly used in semistructural applications in automotive applications because of their good specific strength and modulus, low carbon footprint and recyclability. This research work studies the effects of material treatment(s) on the mechanical behaviors of hemp fiber reinforced polypropylene (PP) composites. The material treatment(s) are realized by chemically treating the hemp fiber with different concentration $\mathrm{NaOH}$ and/or adding maleic anhydride grafted polypropylene (MAPP) to the PP matrix. The purpose of the material treatment(s) is to enhance the bonding between the hemp fibers and the polypropylene matrix which otherwise has low surface energy and limited bonding. The mechanical behaviors are investigated with different combinations of material treatment(s) such as $5 \mathrm{wt} \% \mathrm{MAPP}, 5 \% \mathrm{NaOH}$ treated hemp fiber, $10 \% \mathrm{NaOH}$ treated hemp fiber, and 5\% NaOH+5 wt $\%$ MAPP. $15 \mathrm{wt} \%$ and $30 \mathrm{wt} \%$ hemp fiber loadings are used in the composites with these material treatments. It is found that the material treatment(s) result(s) in composites with better mechanical properties compared to the composites without any treatment(s). The composites with $5 \mathrm{wt} \%$ MAPP addition show the best mechanical properties.

* Selvum Pillay, Corresponding author, pillay@uab.edu, 205-996-5797 Keywords: A. Polymer-matrix composites (PMCs); B. Mechanical properties; E. Compression moulding; E. Surface treatment
\end{abstract}




\section{Introduction}

Natural fibers are receiving increasing attention from engineers because of their low cost, good mechanical properties, low density and biodegradability and have become increasingly suitable alternative reinforcements in composites to synthetic fibers such as glass fibers. Natural fibers, when used with thermoplastic polymers, offer great advantages such as recyclability, low density, good damping, low abrasiveness, enhanced energy recovery, high strength to weight ratio and non-toxicity [1-3]. These renewable natural fibers offer the potential to replace conventional synthetic fibers in various applications including semi-structural automotive components, such as seat back, door inserts, underbody panels, and instrument panels [4-5]. The increasing interest has resulted in large demand of natural fiber composites in the last several years. The amount of natural fiber composite used in 2010 in the European Union was 315,000 tons, which accounted for $13 \%$ of the total composite with any reinforcements materials such as glass, carbon and natural fibers. It was forecasted that approximately 830,000 tons of natural fiber composites will be consumed in Year 2020 and the share will go up to $28 \%$ of the total composite materials [6]. The global market size for natural fiber composites is projected to reach $\$ 5.8$ billion by 2019 with compound annual growth rate of $12.3 \%$ between 2014 and 2019 [7]. Demand for natural fibers will continue to grow due to rising prices of petroleum-based products, strong government support to eco-friendly products, increasingly competitive properties, positive growth of end-use industries, efforts to reduce global warming and higher acceptance among consumers [8-10].

Despite the advantages natural fibers possess over synthetic fibers, natural fibers have several disadvantages that affect their capabilities and properties used in the thermoplastic industry. Some of their main drawbacks are poor binding/adhesion to hydrophobic polymer matrix 
materials such as polypropylene (PP) and an affinity for moisture absorption [11-12]. Researchers have made progress in enhancing the bonding/adhesion between the natural fibers and matrix by material treatments. Alkaline treatments or mercerization are the most commonly used chemical treatment of natural fibers to reinforce thermoplastics [13]. Treating natural fibers with aqueous sodium hydroxide $(\mathrm{NaOH})$ results in the ionization of the hydroxyl group to the alkoxides. It selectively degrades a certain amount of lignin and pectin and facilitates the exposure of reactive $\mathrm{OH}$ groups on the fiber surface. This removal increases the bonding between the fiber and the polymer matrix. In addition to the extraction of lignin and hemicellulose compounds, the alkaline treatment increases the number of reaction sites by increasing the amount of cellulose exposed on the fiber surface [14-15]. Alkaline processing directly affects the cellulosic fibril, degree of crystallinity and extraction of lignin and hemicellulosic compounds. Li et al. [16] studied sisal fibers at different variables such as $\mathrm{NaOH}$ concentrations, temperature, time and pressure. Both of the sisal fibers treated with $5 \%$ aqueous $\mathrm{NaOH}$ for 72 hours at room temperature and another set with $2 \% \mathrm{NaOH}$ for 90 seconds at $200^{\circ} \mathrm{C}$ at 1.5 MPa pressure had a positive effect on the fiber surface by increasing the amorphous cellulose content at the expense of crystalline cellulose [16], which is in agreement with the findings from Sreekala et al. [17]. Ray et al. studied 5\% $\mathrm{NaOH}$ treated jute fibers at various time of treatment. After 4, 6 and 8 hours of treatment with $5 \% \mathrm{NaOH}$, the jute fibers increased their flexural modulus by $12 \%, 68 \%$ and $79 \%$, respectively [18].

Another method to enhance the bonding between the PP and natural fiber for PP based composites is to add maleic anhydride (MA) to the PP matrix [19-21]. This coupling agent acts as a compatibilizer that provides better interfacial bonding and mechanical properties of the composite. The PP chain interacts with the MA and form maleic anhydride grafted 
polypropylene (MAPP). MAPP coupling agent acts as a connection between the polar natural fibers and the nonpolar PP matrix. The fiber surface interacts strongly with the MA functional group through covalent and hydrogen bonding. By polymer chain entanglements, the unreactive PP matrix is then combined with MAPP. The polymer chain entanglement is an important factor in determining the mechanical properties up to and above the glass transition temperature of the matrix [19]. However, the addition of the coupling agent results in viscosity increase and possibly poor fiber wetting. The wettability of the natural fibers can be increased by increasing the surface energy of cellulose fiber to a level close to the surface energy of the matrix [16]. It has been reported that this coupling agent can reduce the water absorption and increase the modulus, hardness, and impact strength of the natural fiber-reinforced composites [19-20]. Sanadi et al. [21] investigated 3 wt $\%$ MAPP with $50 \mathrm{wt} \%$ kenaf fiber reinforced composites. It is found that the tensile strength and Young's modulus increased $88 \%$ and $350 \%$, respectively. Mfala reported that 6 hours of $20 \%$ maleic acid treatment on flax fiber reinforced PP composites increased the flexural strength by $150 \%$ from that of neat PP [22].

The purpose of this work is to study the effects of the material treatment(s), the fiber chemical treatment and/or polymer matrix treatment with coupling agent, on the mechanical properties of the hemp fiber polypropylene matrix composites. The study of fiber length change during the processing is also included.

\section{Material and Methods}

Hemp fibers were supplied by Composites Innovation Centre (CIC), Canada, as the composite reinforcements in a mat format. PP pellets were procured from DOW Chemical Company as the 
matrix material. $\mathrm{NaOH}$ pellets are supplied from Fisher Scientific and Polybond 3200 (MAPP) from Chemtura.

In the chemical treatment, hemp fibers were dried at $50^{\circ} \mathrm{C}$ for 48 hours before any treatment or processing was done. Pre-dried fibers were soaked in $5 \mathrm{wt} \% \mathrm{NaOH}$ and $10 \mathrm{wt} \% \mathrm{NaOH}$ aqueous solution at ambient temperature. $\mathrm{Wt} \% \mathrm{NaOH}$ is defined as the ratio of $\mathrm{NaOH}$ pellet mass to water mass. The fibers were kept immersed in the $\mathrm{NaOH}$ solution for an hour and then thoroughly rinsed with water to remove any traces of alkali on the fiber surface. The treated fibers were then dried at $50^{\circ} \mathrm{C}$ for 48 hours in an air circulation oven. 5 wt $\%$ Polybond 3200 was added to the pre-weighed PP batch with respect to the $15 \mathrm{wt} \%$ and $30 \mathrm{wt} \%$ hemp fiber. The MAPP mixture was then blended with the PP before processing. The nomenclature for each of the samples with different material treatment(s) is listed in the Table 1.

Flexural testing was conducted based on ASTM D790-Standard Test Methods for Flexural Properties of Unreinforced and Reinforced Plastics and Electrical Insulating Materials using an INSTRON SATEC APEX T5000 testing frame with a crosshead speed of $5 \mathrm{~mm} / \mathrm{min}$. Five specimens were prepared and tested according to the standard. Tensile samples were prepared and tested based on ASTM D638-Standard Test Method for Tensile Properties of Plastics using an MTS 810 Material Test System with a MTS Extensometer to measure the strain. Five dogboned specimens were prepared from each material treatment variance, and the average tensile strength and modulus were calculated.

Figure 1 shows the overall process and the manufactured hemp fiber PP composite plates from which the testing samples were prepared. In the process, hemp fibers and PP pellets were fed into a twin extruder and compounded. This compounding process results in the impregnation of the fibers with melted polypropylene polymer. The compounded mixture was extruded through a 
rectangular shaped die and cooled to form tape. The compounded tape form was chopped into 25 mm long pieces and fed into a low shear plasticator. After the charge was extruded in the low shear plasticator which was set to $180^{\circ} \mathrm{C}$ for melting PP, it was then placed into a mold (152 $\mathrm{x}$ $152 \mathrm{~mm}$ ) and compression molded into a plate at a pressure of $17 \mathrm{MPa}$. The compression mold temperature was set at $77^{\circ} \mathrm{C}$. The compression molded plate was then demolded after 2-minute hold. All of the molded plates have similar thickness of approximately $6 \mathrm{~mm}$. The testing samples were prepared with the same orientation from plate to plate to eliminate the effect of possible directionality resulted from material flow.

\section{Results and Discuss}

Figure 2 shows the SEM images of the surfaces of the untreated, $5 \mathrm{wt} \% \mathrm{NaOH}$ and $10 \mathrm{wt} \%$ $\mathrm{NaOH}$ treated hemp fibers. The untreated fibers, as shown in Figure 2a, have uneven deposit impurities on its surface. In contrast, the alkali treatment of the fibers led to a cleaner, yet rougher surface as shown in Figures $2 b$ and $2 c$. The increase in $\mathrm{NaOH}$ concentration removed most surface impurities and resulted in rougher and cleaner surface. The alkali treatment is expected to increase the surface roughness by distributing the hydrogen bonding in the network structure to provide additional sites for mechanical interlocking [23]. The alkaline treatment also results in defibrillation as shown in Figure $2 \mathrm{~b}$ and $2 \mathrm{c}$ and therefore increased surface area. The increased surface area of the treated fiber surface results in increased bonding with thermoplastic polymer matrix [24]. The FTIR spectrums for the treated and untreated hemp fibers are shown in Figure 3. The hemp fibers treated with $5 \mathrm{wt} \%$ and $10 \mathrm{wt} \% \mathrm{NaOH}$ exhibit nearly identical spectra.

The figure also shows that the peak area in the range of $3200-3500 \mathrm{~cm}^{-1}$ of the treated fibers caused by hydroxyl group $-\mathrm{OH}$ stretching vibration is much intensified compared to the 
untreated fibers, indicating that $\mathrm{NaOH}$ treatment has reduced impurities and resulted in the increasing percentage of hydroxyl group [25]. Similar intensification of the peaks at wave number $1104 \mathrm{~cm}^{-1}$, which is assigned to the C-C-C stretching vibration of cellulose [26], has also been noticed for treated fibers. The absorption peak of cellulose at about $1422 \mathrm{~cm}^{-1}$ and 1159 $\mathrm{cm}^{-1}$ also have more distinct appearance after the $\mathrm{NaOH}$ treatment because of increasing amount of cellulose [27].

The fiber length before and after the twin screw compounding and compression molding processes was investigated. It would be very challenging to apply the typical burn off or acid digestion test to extract hemp fiber from hemp/PP composite and analyze fiber length due to the poor thermal and chemical stability of the hemp fibers. Therefore, the PP is replaced with polyvinyl alcohol (PVA), a water-soluble polymer that has been used in composite applications [28-29]. It has slightly higher viscosity than PP when both of the polymers are melted at the same temperature around $190^{\circ} \mathrm{C}[30]$. The PVA can then be washed out of the products from each stage of the processes leaving the hemp fibers to be analyzed. Figure 4 and 5 show the distribution of fiber lengths before and after compounding and compression molding process, respectively. Fiber lengths after the compounding process were mainly between $20-30 \mathrm{~mm}$; after the molding process, fiber lengths were mainly between 10-20 $\mathrm{mm}$. Table 2 shows the average fiber length and diameter before and after twin screw compounding and compression molding processes. Although the fiber length attrition inevitably exists during the processes, the hemp fiber length retained over $40 \%$ of its original length. The average aspect ratio (length/diameter) of the hemp fibers after the final process is more than 500.

Figure 6-9 show the comparison of flexural modulus, flexural strength, tensile modulus and tensile strength for all of the samples with different material treatment(s) listed in Table 1. 
Sample $15-5 \mathrm{NaOH}$ and $15-10 \mathrm{NaOH}$ show obvious increase in tensile properties and flexural properties compared to $15-\mathrm{UT}$, which indicates that the chemical treatment using $\mathrm{NaOH}$ led to better bonding between the fiber and the matrix.

The addition of the MAPP coupling agent showed good results compared to the $\mathrm{NaOH}$ treated hemp fibers. 15-5MAPP had the highest flexural strength of 35.4 MPa, flexural modulus of 1.12 $\mathrm{GPa}$, tensile strength of $24.2 \mathrm{MPa}$ and tensile modulus of $2.23 \mathrm{GPa}$. The surface of the fiber with MAPP addition allowed direct bonding between the MA functional group and microfibrils cellulose $\mathrm{OH}$ groups [16]. This interaction allowed the flexural and tensile strength and modulus properties to increase by $37 \%, 37 \%, 68 \%$ and $213 \%$, respectively, compared to PP. $15-5 \mathrm{NaOH}-$ 5MAPP had comparable flexural properties with 15-5MAPP although its tensile properties are roughly the same values as $15-5 \mathrm{NaOH}$.

The SEM images in Figure 10 show the fracture surfaces of the $15 \mathrm{wt} \%$ hemp fiber reinforced PP composites. Figure 10a shows 15-UT with poor fiber-matrix interfacial adhesion. Fiber breakage and some fiber pullout/debonding were evident. The protruding hemp fibers with the gaps around the fiber indicated poor bonding of the PP matrix to the fibers. Both $15-5 \mathrm{NaOH}$ and $15-10 \mathrm{NaOH}$ showed an improvement of the bonding between fiber and matrix as shown in Figures $10 \mathrm{~b}$ and $10 \mathrm{c}$, but there was still gap between the fiber and matrix. Figure 10d shows $15-$ 5MAPP with the best fiber-matrix interfacial adhesion. The PP adhered to the surface of the hemp fibers without any gaps present. There was less damage on the fibers than the 15-UT, 15$5 \mathrm{NaOH}$ and $15-10 \mathrm{NaOH}$. MAPP addition greatly improved the fiber-matrix adhesion thus increasing the mechanical properties as shown in Figure 6-9. Figure 10e shows relatively good interfacial bonding in $15-5 \mathrm{NaOH}-5 \mathrm{MAPP}$ with some fiber pullouts. Without chemical 
modifications or coupling agent additives to hemp fibers, the interfacial bonding between fiber and matrix was poor and lowered the mechanical properties of the composite.

A fiber loading of $30 \mathrm{wt} \%$ with PP matrix was processed and tested to compare with $15 \mathrm{wt} \%$ fiber loading. $30 \mathrm{wt} \%$ fiber variances were minimized into four sets: $30-\mathrm{UT}, 30-5 \mathrm{NaOH}, 30-$ 5MAPP and 30-5NaOH-5MAPP. The abbreviation for each variance is listed in Table 1 . The untreated set, 30-UT, was selected as the control sample to compare properties with $30-5 \mathrm{NaOH}$ (5 wt $\% \mathrm{NaOH}$ treated fibers), 30-5MAPP (5 wt $\%$ MAPP added) and 30-5NaOH-5MAPP (5 wt $\%$ $\mathrm{NaOH}$ treated fibers and $5 \mathrm{wt} \%$ MAPP added).

Flexural and tensile properties were evaluated for the composites with $30 \mathrm{wt} \%$ fiber loading and compared with the results for the composites with $15 \mathrm{wt} \%$ fiber loading. Figures 11-14 compare the flexural and tensile properties of PP, $15 \mathrm{wt} \%$ and $30 \mathrm{wt} \%$ hemp fiber reinforced PP composites. Overall, the composites with $30 \mathrm{wt} \%$ fiber loading have higher tensile and flexural properties than the neat PP and the composites with $15 \mathrm{wt} \%$ fiber loading as expected. 30-UT and $30-5 \mathrm{NaOH}$ samples did not have a significant increase in properties when the weight percentage increased as was evident in the samples with MAPP addition. 30-5MAPP had a 40\%, $70 \%, 32 \%$ and $27 \%$ increase, respectively, for the flexural strength and modulus and tensile strength and modulus compared to 15-5MAPP. In addition, 30-5MAPP had a 91\%, 132\%, 122\% and $297 \%$ increase, respectively, for the flexural strength and modulus and tensile strength and modulus compared to PP. Both of the composites with MAPP only, 15-5MAPP and 30-5MAPP, show better properties than the other material variances with the same fiber loading, even though their hemp fibers are not treated with $\mathrm{NaOH}$. The high aspect ratio of the hemp fibers is probably attributed to their good properties. The longer fibers (larger surface area) retained after processing are effective enough to convey the load from the matrix to the fibers and therefore 
provide good mechanical properties. The composites with $\mathrm{NaOH}$ treated fibers and MAPP do not show any advantage over the composites with MAPP only. Although the composites with $\mathrm{NaOH}$ treated fibers and MAPP have comparable flexural properties to the composites with MAPP, their tensile properties are slightly lower. However, the results indicate that it is possible to eliminate the $\mathrm{NaOH}$ treatment on the natural fibers without sacrificing their composite material properties if the fiber length is retained during the processing.

Figure 15 shows the SEM images of the fracture surfaces of the $30 \mathrm{wt} \%$ hemp fiber reinforced PP composites. Both $30-\mathrm{UT}$ and $30-5 \mathrm{NaOH}$ specimens had fiber pullouts and poor interfacial bonding where fiber breakage occurred as shown in Figures 15a and 15b. The specimens containing MAPP had great interfacial bonding and wetting of the fibers as shown in Figures $15 \mathrm{c}$ and $15 \mathrm{~d}$. There were no gaps between the fiber and matrix on the interface where fiber pullout and breakage were evident. This phenomenon coincided with the noticeable increase in their mechanical properties.

\section{Conclusions}

This research studied the effect of the material treatment(s) on the tensile and flexural properties of hemp fiber reinforced polypropylene composites. Alkaline fiber treatment and/or the addition of a maleated coupling agent proved to improve the interfacial adhesion between the fiber and the matrix in the hemp fiber reinforced PP composite and increase its flexural and tensile properties. The composite with $30 \mathrm{wt} \%$ fiber loading results in higher mechanical properties, as expected, compared to the composites with $15 \mathrm{wt} \%$ fiber loading with the same material treatment(s) or neat PP. 15-5MAPP (5 wt $\%$ MAPP + $15 \mathrm{wt} \%$ fiber) had a $37 \%, 37 \%$, $68 \%$ and $213 \%$ increase in flexural strength and modulus and tensile strength and modulus compared to 
neat PP. 30-5MAPP had a $91 \%, 132 \%, 122 \%$ and $297 \%$ increase, respectively, for the flexural strength and modulus and tensile strength and modulus compared to neat PP. SEM images showed that both of the samples have great interfacial adhesion due to wetting of the fibers and no apparent gaps between the fiber and matrix after fiber breakage, which coincided with the high mechanical properties. The material treatment(s) result(s) in composites with better mechanical properties compared to the composites without any treatment(s). Both of the composites with MAPP only, 15-5MAPP and 30-5MAPP, show better properties than the other material variances with the same fiber loading.

\section{Acknowledgements}

The authors would like to acknowledge the financial support from National Science Foundation CREST Program and Composites Innovation Centre (CIC), Canada.

\section{References}

1. Deepa B, Pothan LA, Mavelil-Sam R, Thomas S. Structure, properties and recyclability of natural fibre reinforced polymer composites. In: Fainleib A, Grigoryeva O, Editor. Recent Developments in Polymer Recycling. Transworld Research Network, 2011, p.101-120.

2. Rowell RM, Caulfield DF, Jacobson RE. Utilization of natural fibers in plastic composites: problems and opportunities. In Lignocellulosic-Plastics Composites. Brazil: 1997. p.23-51.

3. Verma D, Gope PC, Maheshwari MK, Sharma RK. Bagasse fiber composites-a review. Journal of Materials and Environmental Science 2012; 3(6):1079-1092.

4. Karus M, Kaup M. Natural fibres in the European automotive industry. Journal of Industrial Hemp 2002; 7(1):119-131.

5. Hill K, Swiecki B, Cregger J. The bio-based materials automotive value chain. Center for Automotive Research; www.cargroup.org/?module=Publications\&event=View\&pubID=29. [Accessed in August 2016]. 
6. Carus M, Scholz L. Targets for bio-based composites and natural fibres. Biowerkstoff report. ISSN 1867-1217, 8th ed.; 2011. p.24.

7. Natural Fiber Composites Market by Type (Wood Fiber and Non-Wood Fiber), Manufacturing Process (Compression Molding, Injection Molding, and Others), Application (Building \& Construction, Automotive, and Electrical \& Electronics), and Region - Global Forecasts to 2021. http://www.prnewswire.com/news-releases/natural-fiber-composites-market-worth-583-billionby-2019-285331091.html, accessed in Dec 2016.

8. Lucintel. Opportunities in natural fiber composites. March 2011. Accessed in Aug 2016. http://www.lucintel.com/LucintelBrief/PotentialofNaturalfibercomposites-Final.pdf.

9. Kim SJ, Moon JB, Kim GH, Ha CS. Mechanical properties of polypropylene/natural fiber composites: Comparison of wood fiber and cotton fiber. Polymer Testing 2008; 27(7):801-806.

10. Ozen E, Kiziltas A, Kiziltas EE, Gardner DJ. Natural fiber blendsfilled engineering thermoplastic composites for the automobile industry. In: Proceedings of SPE ACCE Conference, Troy, 2012. p.1-12.

11. Westman MP, Fifield LS, Simmons KL, Laddha SG, Kafentzis TA. Natural fiber composites: a review. Pacific Northwest National Laboratory, Richland, 2010.

12. Georgopoulos S, Tarantili PA, Avgerinos E, Andreopoulos AG, Koukios EG. Thermoplastic polymers reinforced with fibrous agricultural residues. Polymer Degradation and Stability 2005; 90(2):303-312.

13. Ahad NAB, Parimin N, Mahmed N, Ibrahim SS, Nizzam K, Ho YM. Effect of chemical treatment on the surface of natural fiber. Journal of Nuclear and Related Technologies 2009; 6(1):155-158.

14. Kalia S, Kaith BS, Kaur I. Pretreatments of natural fibers and their applications as reinforcing material in polymer composites - a review. Polymer Engineering \& Science 2009; 49(7):1253-1272.

15. Suardana N, Piao Y, Lim JK. Mechanical properties of hemp fibers and hemp/PP composites: effects of chemical surface treatment. Materials Physics and Mechanics 2011; 11(1):1-8.

16. Li X, Tabil LG, Panigrahi S. Chemical treatments of natural fiber for use in natural fiberreinforced composites: a review. Journal of Polymers and the Environment 2007; 15(1):25-33.

17. Sreekala MS, Kumaran MG, Joseph S, Jacob M, Thomas S. Oil palm fibre reinforced phenol formaldehyde composites: influence of fibre surface modifications on the mechanical performance. Applied Composite Materials 2000; 7(5-6):295-329. 
18. Ray D, Sarkar BK, Rana AK, Bose NR. Effect of alkali treated jute fibres on composite properties. Bulletin of materials science 2001; 24(2):129-135.

19. Holbery J, Houston D. Natural-fiber-reinforced polymer composites in automotive applications. JOM 2006; 58(11):80-86.

20. Mishra S, Naik JB, Patil YP. The compatibilising effect of maleic anhydride on swelling and mechanical properties of plant-fiber-reinforced novolac composites. Composites Science and Technology 2000; 60(9):1729-1735.

21. Sanadi AR, Caulfield DF, Jacobson RE, Rowell RM. Renewable agricultural fibers as reinforcing fillers in plastics: mechanical properties of kenaf fiber-polypropylene composites. Industrial \& Engineering Chemistry Research 1995; 34(5):1889-1896.

22. Mfala N. Characterization, chemical modification, and process optimization of flax fiber natural composites. Internal report, University of Alabama at Birmingham, Birmingham, 2011.

23. Beckermann G. Performance of hemp-fibre reinforced polypropylene composite materials. The University of Waikato, New Zealand, 2007.

24. Cao Y, Shibata S, Fukumoto I. Mechanical properties of biodegradable composites reinforced with bagasse fibre before and after alkali treatments. Composites Part A: Applied Science and Manufacturing 2006; 37(3):423-429.

25. Ma ZZ, Pan GW, Xu HL, Huang YL, Yang YQ. Cellulosic fibers with high aspect ratio from cornhusks via controlled swelling and alkaline penetration. Carbohyd. Polym. 2015; 124:50-56.

26. Cai M, Takagi H, Nakagaito AN, Katoh M, Ueki T, Waterhouse GIN, Li Y. Influence of alkali treatment on internal microstructure and tensile properties of abaca fibers. Ind. Crop. Prod. $2015 ; 65: 27-35$.

27. Baek BS, Park JW, Lee BH, Kim HJ. Development and application of green composites: using coffee ground and bamboo flour. J. Polym. Environ. 2013; 21:702-709.

28. Yan C, Sun L, Chiparus O, Negulescu I, Yachmenev V, Warnock M. Kenaf/ramie composite for automotive headliner. Journal of Polymers and the Environment 2005; 13(2):107-114.

29. Kong I, Shang JTB, Tshai KY. Study of properties of coconut fibre reinforced poly (vinyl alcohol) as biodegradable composites. Journal of Engineering and Applied Sciences 2016; 11(1):135-143.

30. $\mathrm{Ku} \mathrm{TH}$, Lin $\mathrm{CA}$. Rheological properties of thermoplastic polyvinyl alcohol and polypropylene blend melts in capillary extrusions. Journal of Polymer Research 2015; 12(1):2329. 
Table 1. Nomenclature used for hemp fiber/PP with $15 \mathrm{wt} \%$ and $30 \mathrm{wt} \%$ fiber loading.

\begin{tabular}{cc|cc}
\hline Abbreviation & $\mathbf{1 5}$ wt \% Fiber Loading & Abbreviation & 30 wt \% Fiber Loading \\
\hline PP & Neat PP & & \\
\hline PP-5MAPP & Neat PP + 5 wt \% MAPP & & \\
\hline $15-\mathrm{UT}$ & Untreated Hemp Fiber & $30-\mathrm{UT}$ & Untreated Hemp Fiber \\
\hline $15-5 \mathrm{NaOH}$ & $5 \mathrm{wt} \% \mathrm{NaOH}$ & $30-5 \mathrm{NaOH}$ & $5 \mathrm{wt} \% \mathrm{NaOH}$ \\
\hline $15-10 \mathrm{NaOH}$ & $10 \mathrm{wt} \% \mathrm{NaOH}$ & & $5 \mathrm{wt} \% \mathrm{MAPP}$ \\
\hline $15-5 \mathrm{MAPP}$ & $5 \mathrm{wt} \% \mathrm{MAPP}$ & $30-5 \mathrm{MAPP}$ & \\
\hline $\begin{array}{c}15-5 \mathrm{NaOH}- \\
5 \mathrm{MAPP}\end{array}$ & $5 \mathrm{wt} \% \mathrm{NaOH}+5 \mathrm{wt} \% \mathrm{MAPP}$ & $\begin{array}{c}30-5 \mathrm{NaOH}- \\
5 \mathrm{MAPP}\end{array}$ & $5 \mathrm{wt} \% \mathrm{NaOH}+5 \mathrm{wt} \% \mathrm{MAPP}$ \\
\hline
\end{tabular}


Table 2. Fiber length and diameter before and after compounding and compression molding process.

\begin{tabular}{lccc}
\hline \multicolumn{2}{c}{ Processes } & Length $(\mathbf{m m})$ & Diameter $(\mathbf{m m})$ \\
\hline Twin Screw & Before & 36.4 & 0.04 \\
Compounding & After & 29.1 & 0.03 \\
& & & \\
Compression & Before & 17.4 & 0.03 \\
Molding & After & 15.7 & 0.03 \\
\hline
\end{tabular}




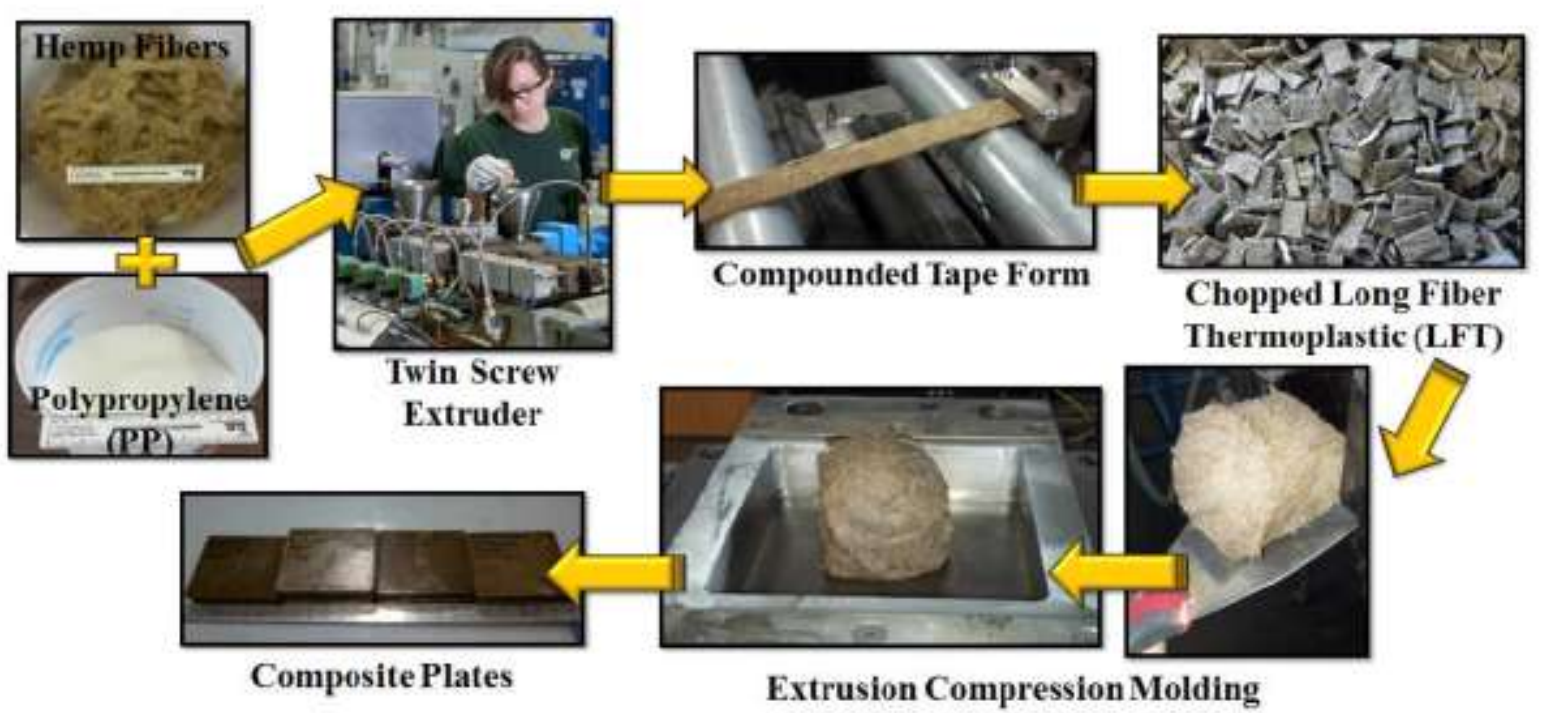

Figure 1. Compounding-extrusion-compression molding process of hemp fiber reinforced PP composites. 

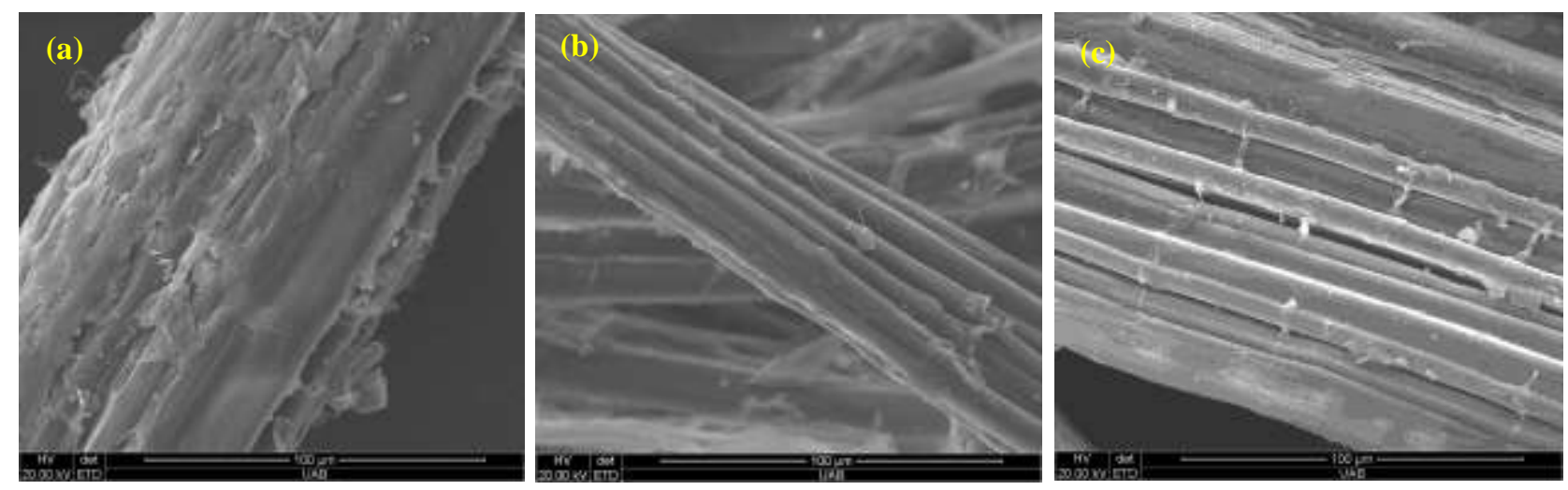

Figure 2. SEM images of hemp fiber surfaces of (a) untreated, (b) $5 \mathrm{wt} \% \mathrm{NaOH}$ and (c) $10 \mathrm{wt} \%$ $\mathrm{NaOH}$. 


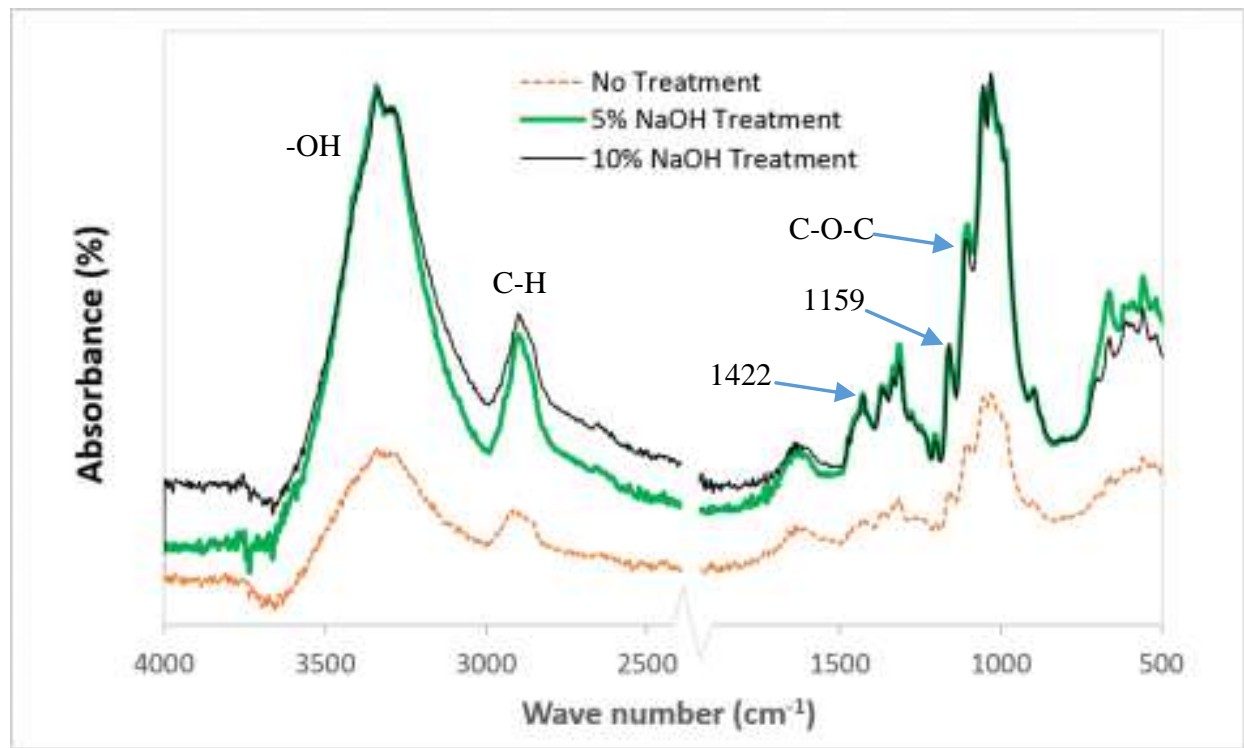

Figure 3. FTIR spectrums for the hemps without and with treatments. 


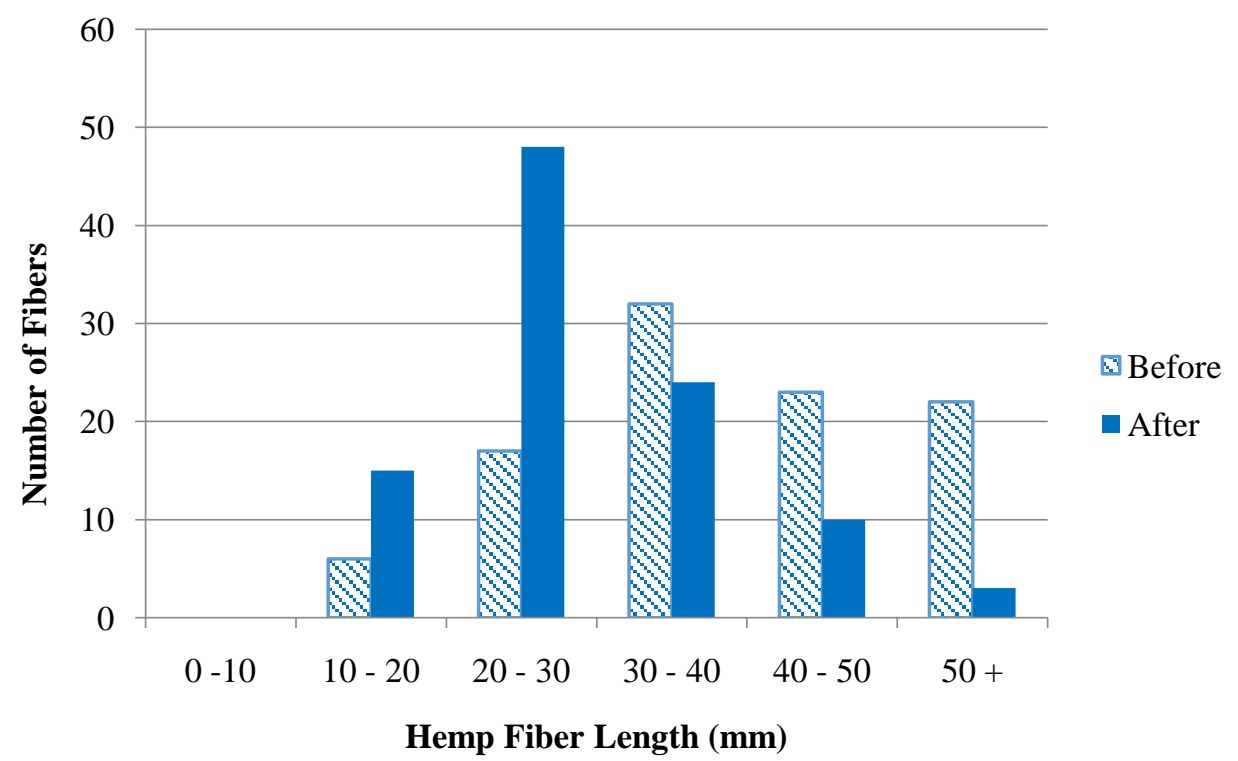

Figure 4. Hemp fiber length before and after twin screw compounding process. 


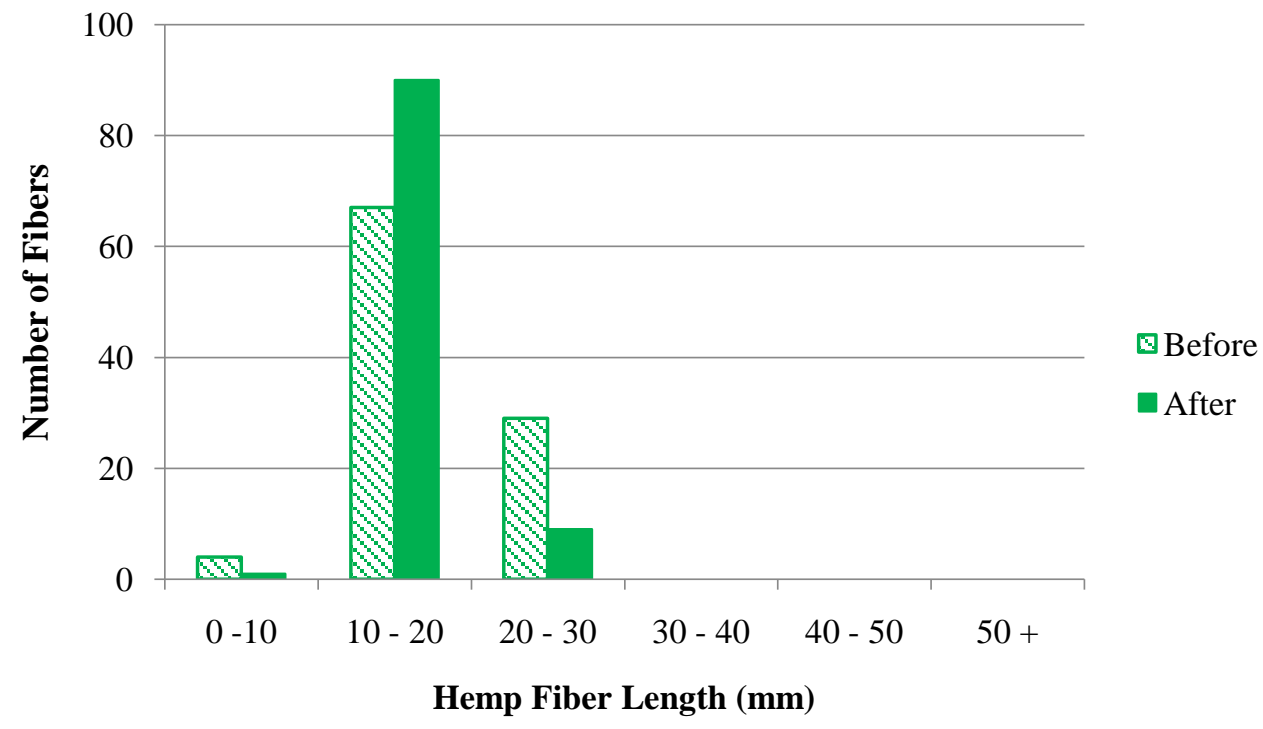

Figure 5. Hemp fiber length before and after compression molding process. 


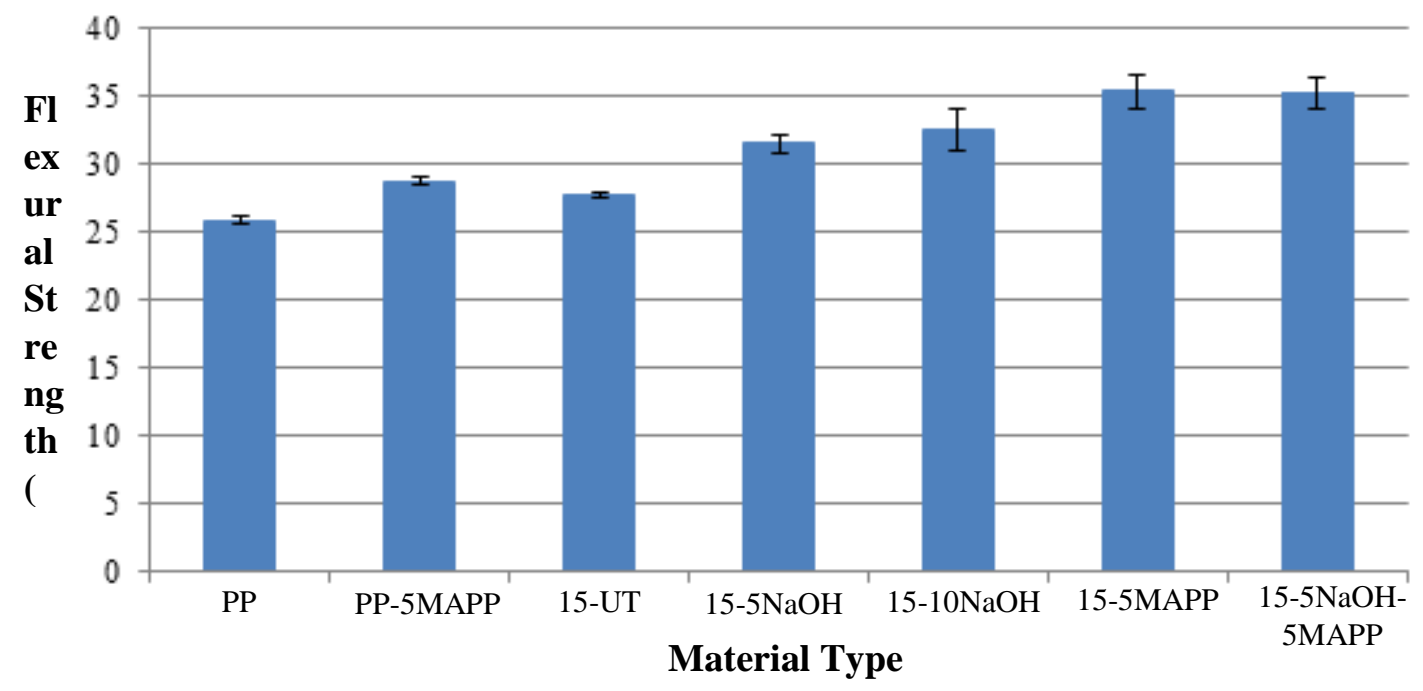

Figure 6. Flexural strength of $15 \mathrm{wt} \%$ hemp fiber reinforced PP composite variances. 


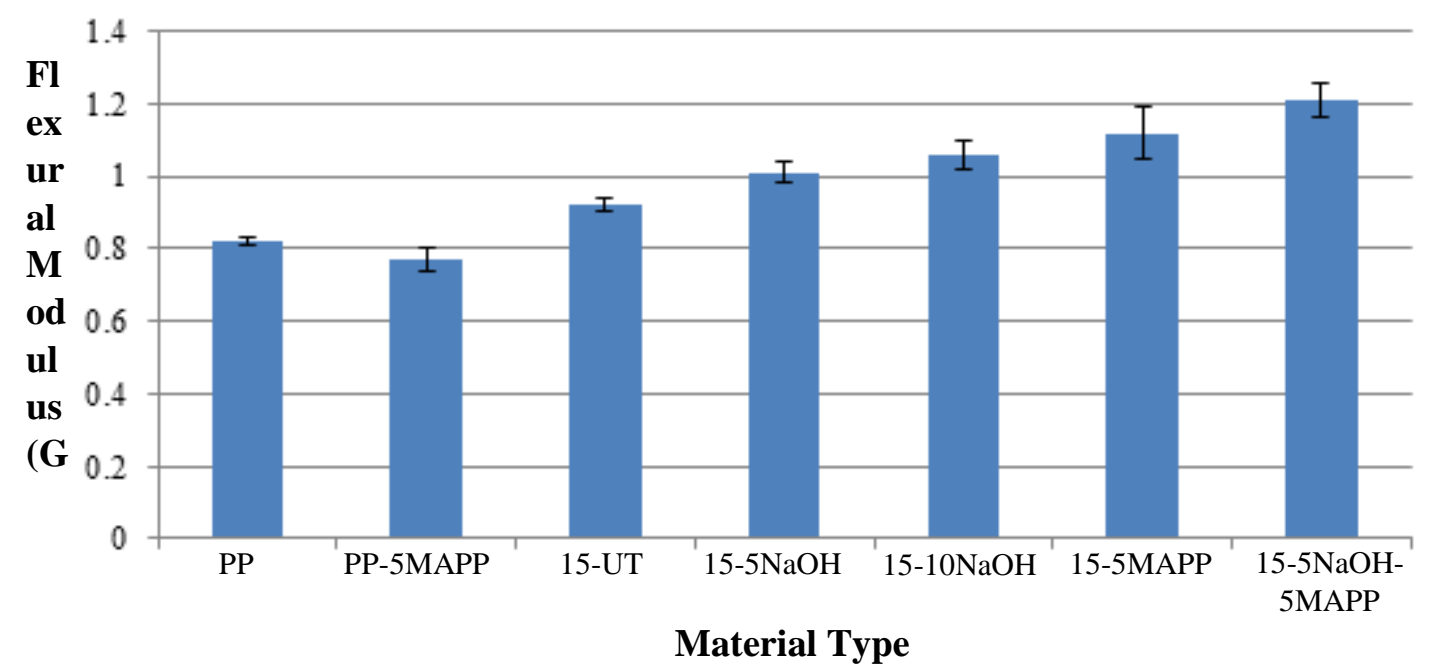

Figure 7. Flexural modulus of $15 \mathrm{wt} \%$ hemp fiber reinforced PP composite variances. 


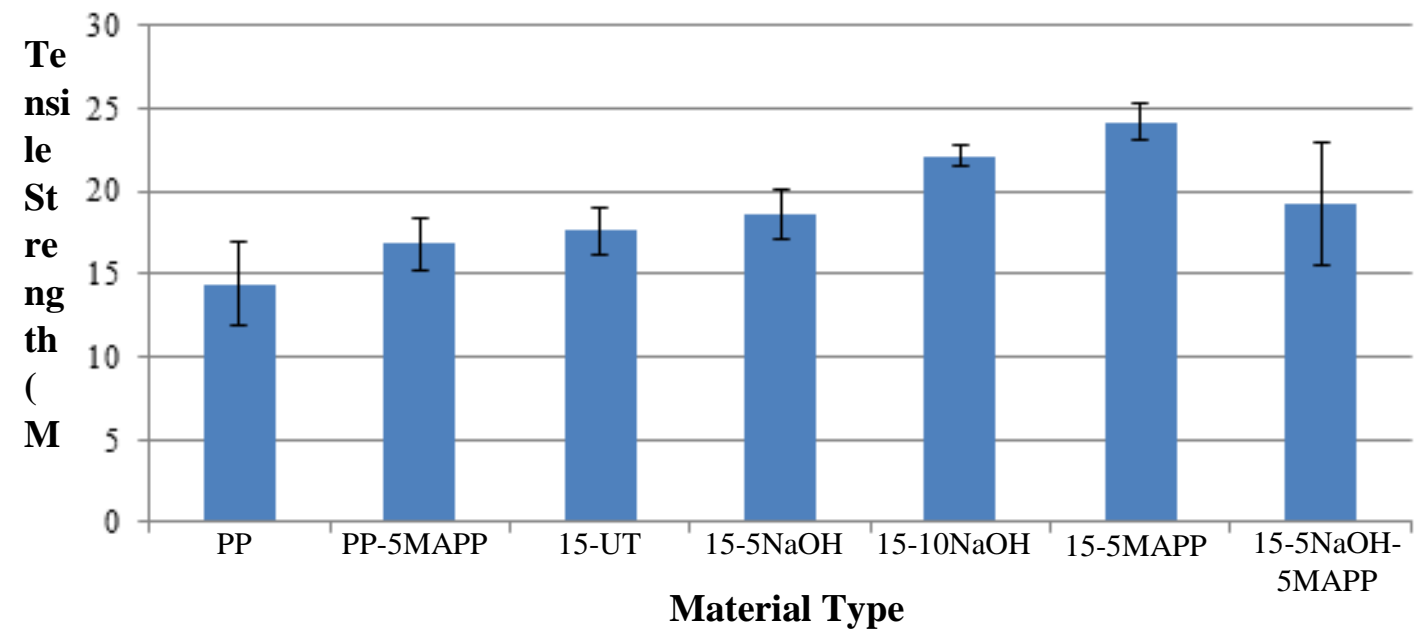

Figure 8. Tensile strength of $15 \mathrm{wt} \%$ hemp fiber reinforced PP composite variances. 


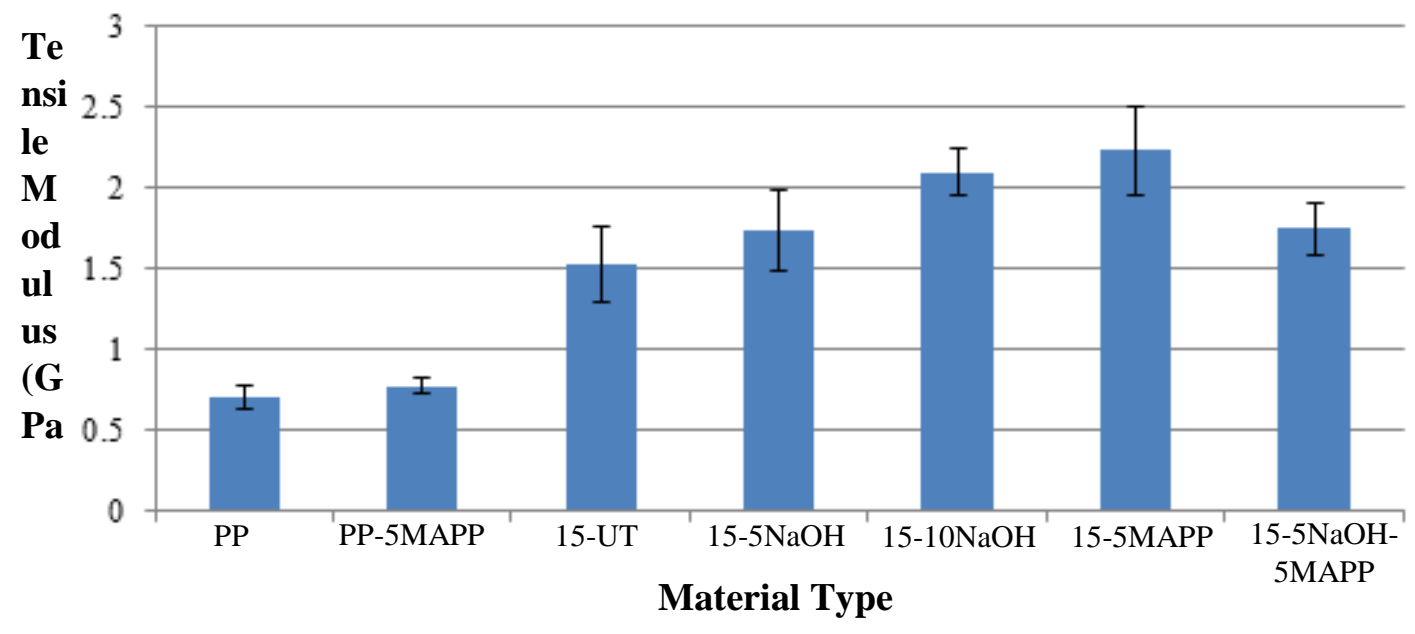

Figure 9. Tensile modulus of $15 \mathrm{wt} \%$ hemp fiber reinforced PP composite variances. 

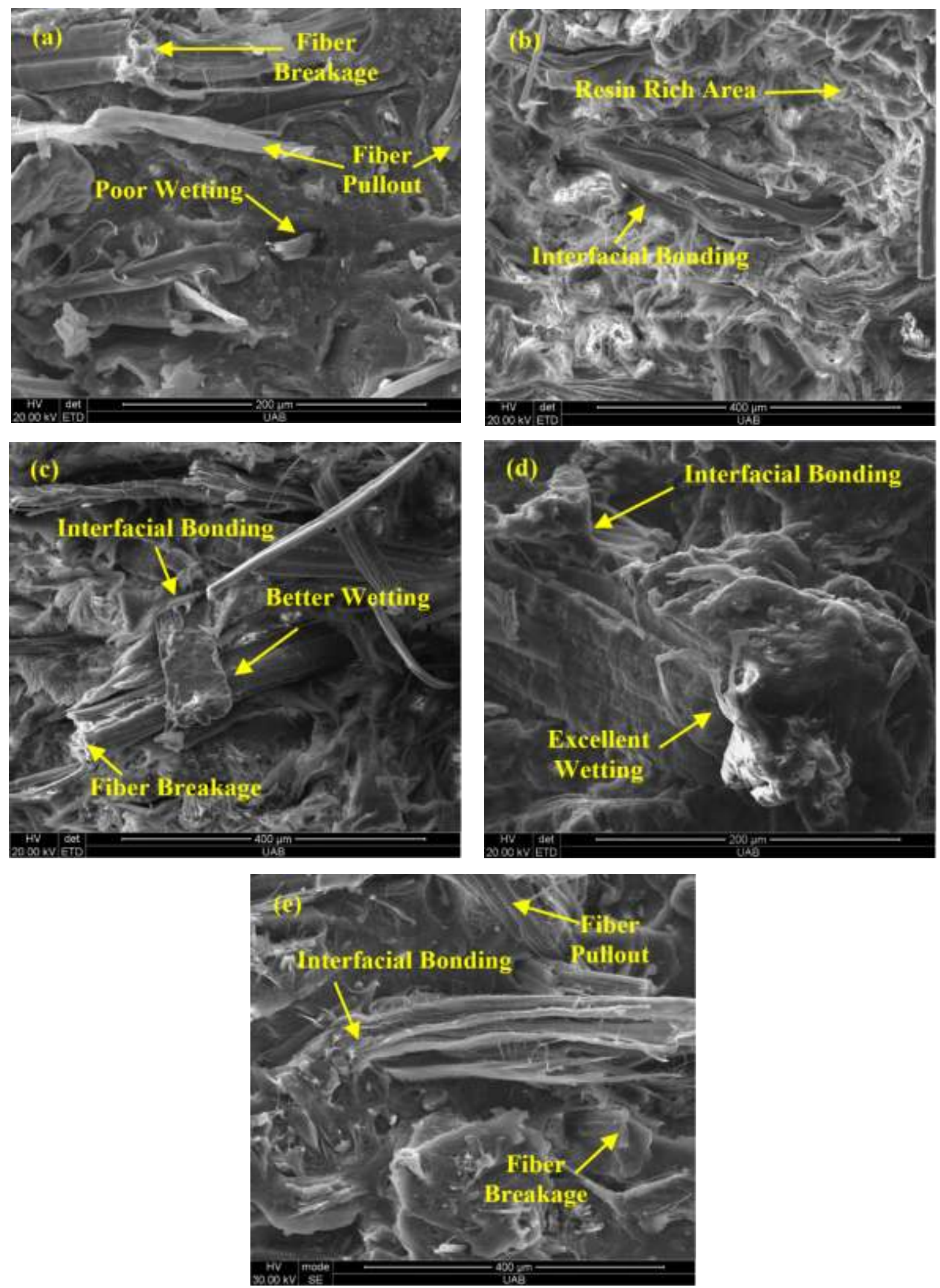

Figure 10. SEM images of $15 \mathrm{wt} \%$ hemp fiber reinforced PP composite fiber fracture surfaces of (a) $15-\mathrm{UT}$, (b) $15-5 \mathrm{NaOH}$, (c) $15-10 \mathrm{NaOH}$, (d) $15-5 \mathrm{MAPP}$ and (e) $15-5 \mathrm{NaOH}-5 \mathrm{MAPP}$. 


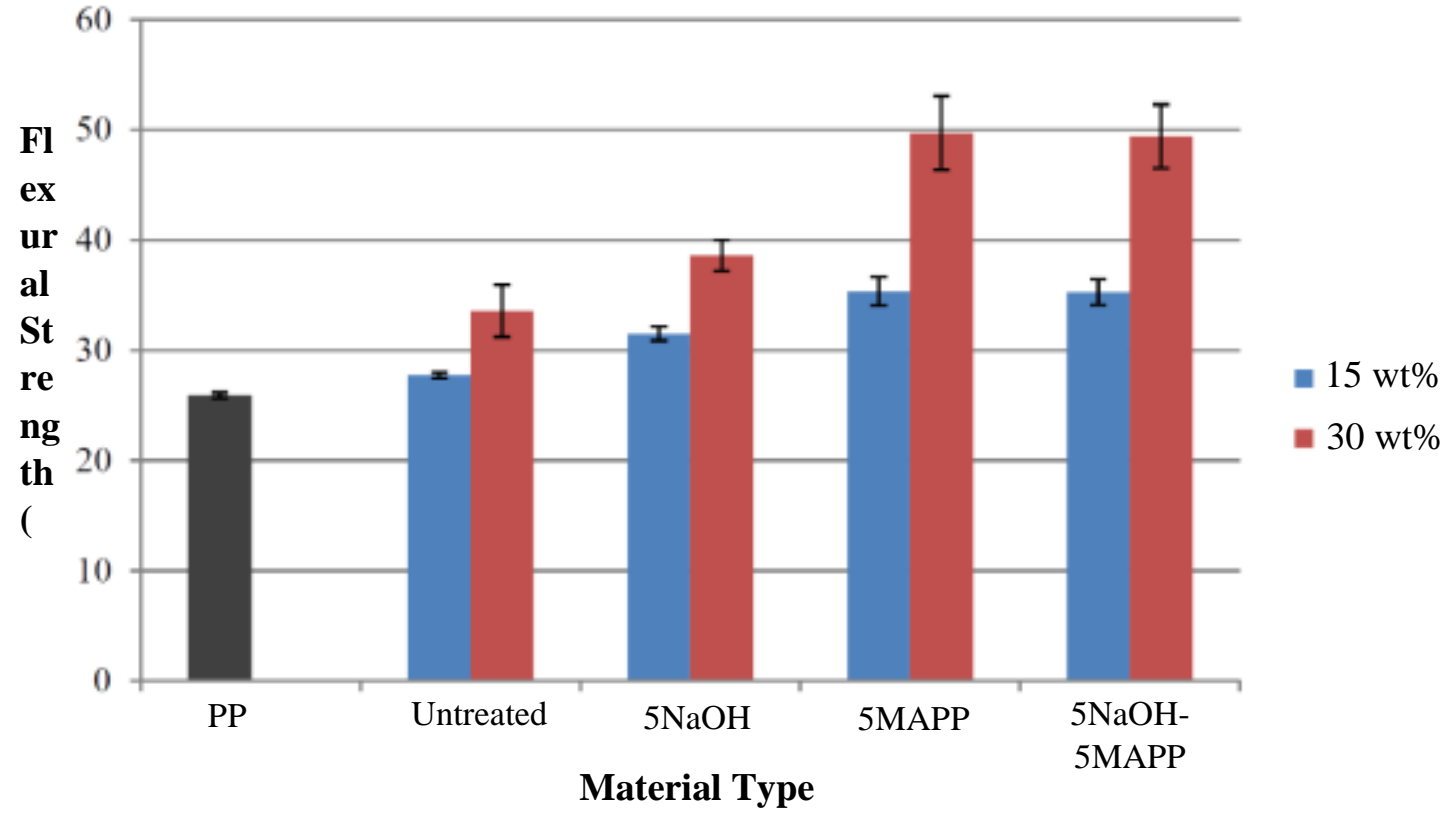

Figure 11. Flexural strength comparison of PP, $15 \mathrm{wt} \%$ and $30 \mathrm{wt} \%$ hemp fiber reinforced PP composites. 


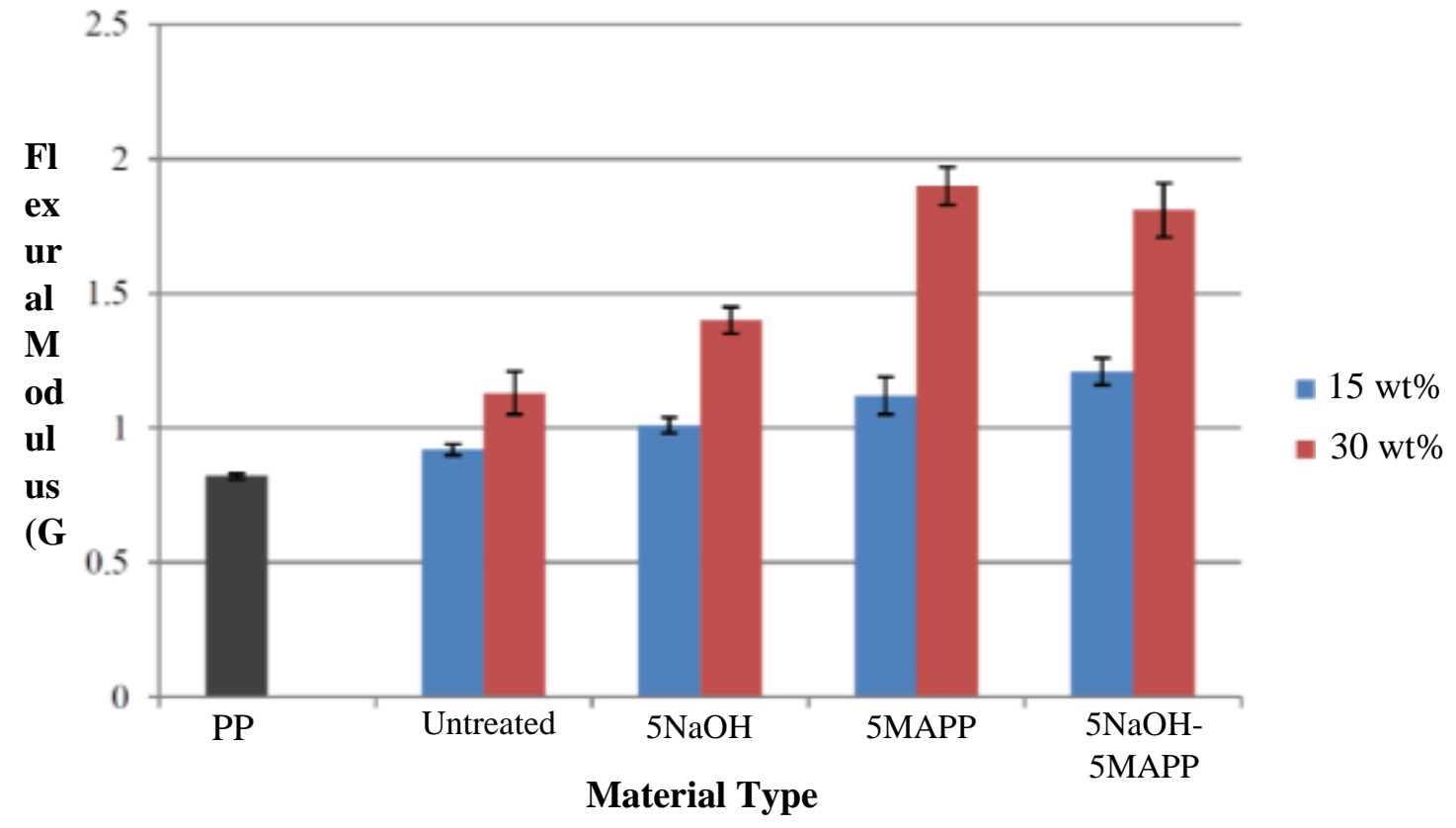

Figure 12. Flexural modulus comparison of PP, $15 \mathrm{wt} \%$ and $30 \mathrm{wt} \%$ hemp fiber reinforced PP composites. 


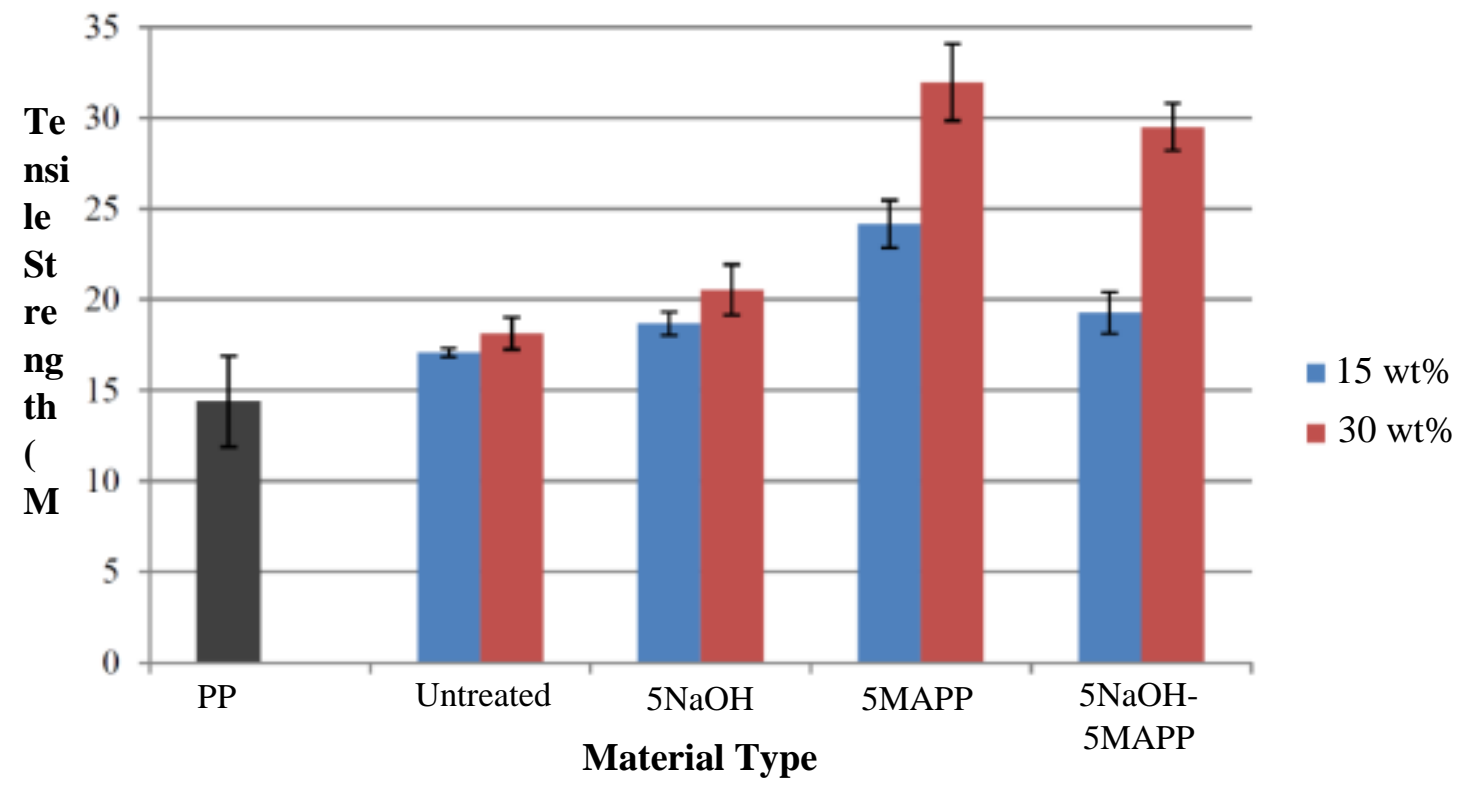

Figure 13. Tensile strength comparison of PP, $15 \mathrm{wt} \%$ and $30 \mathrm{wt} \%$ hemp fiber reinforced PP composites. 


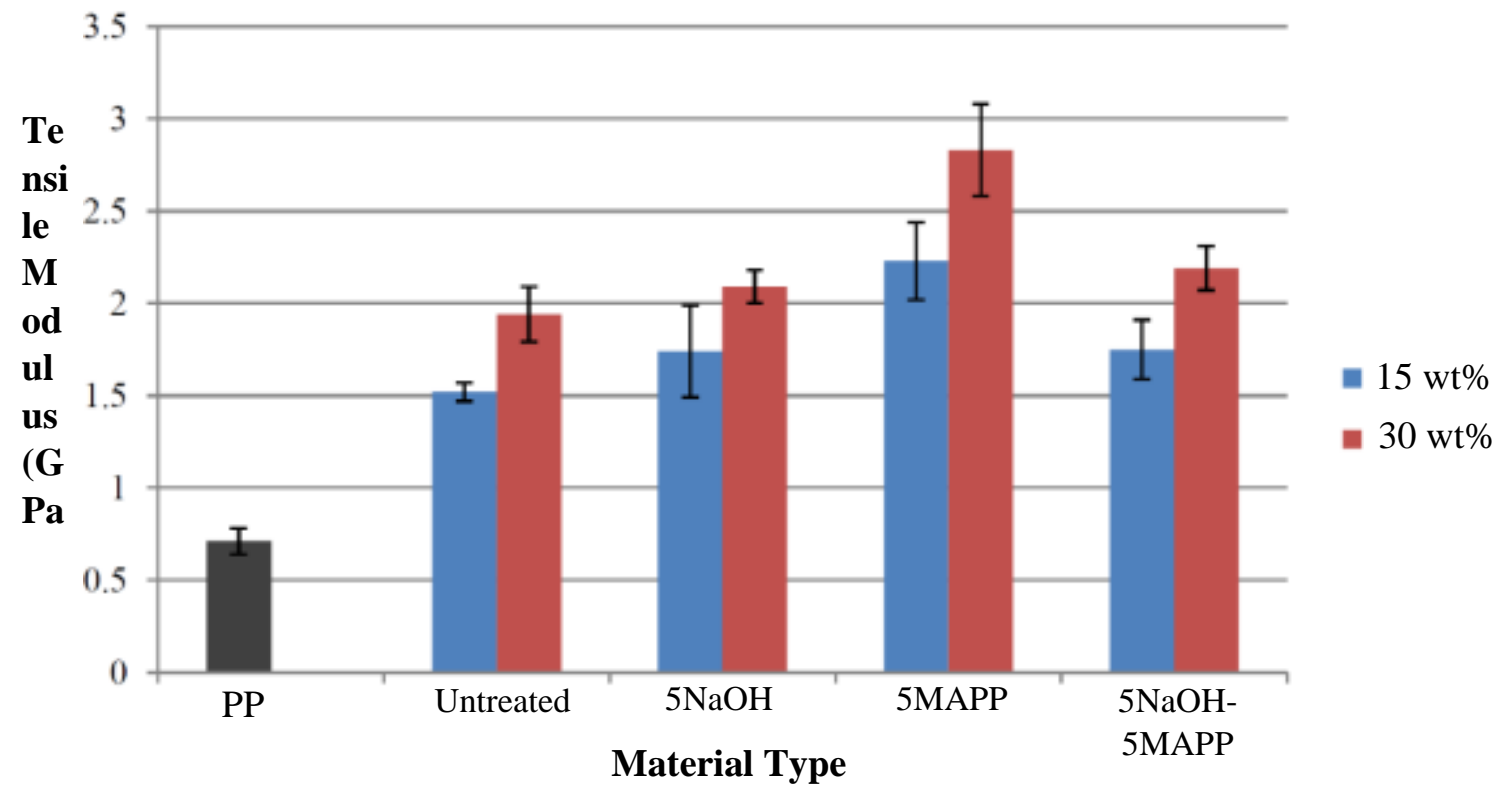

Figure 14. Tensile modulus comparison of PP, $15 \mathrm{wt} \%$ and $30 \mathrm{wt} \%$ hemp fiber reinforced PP composites. 

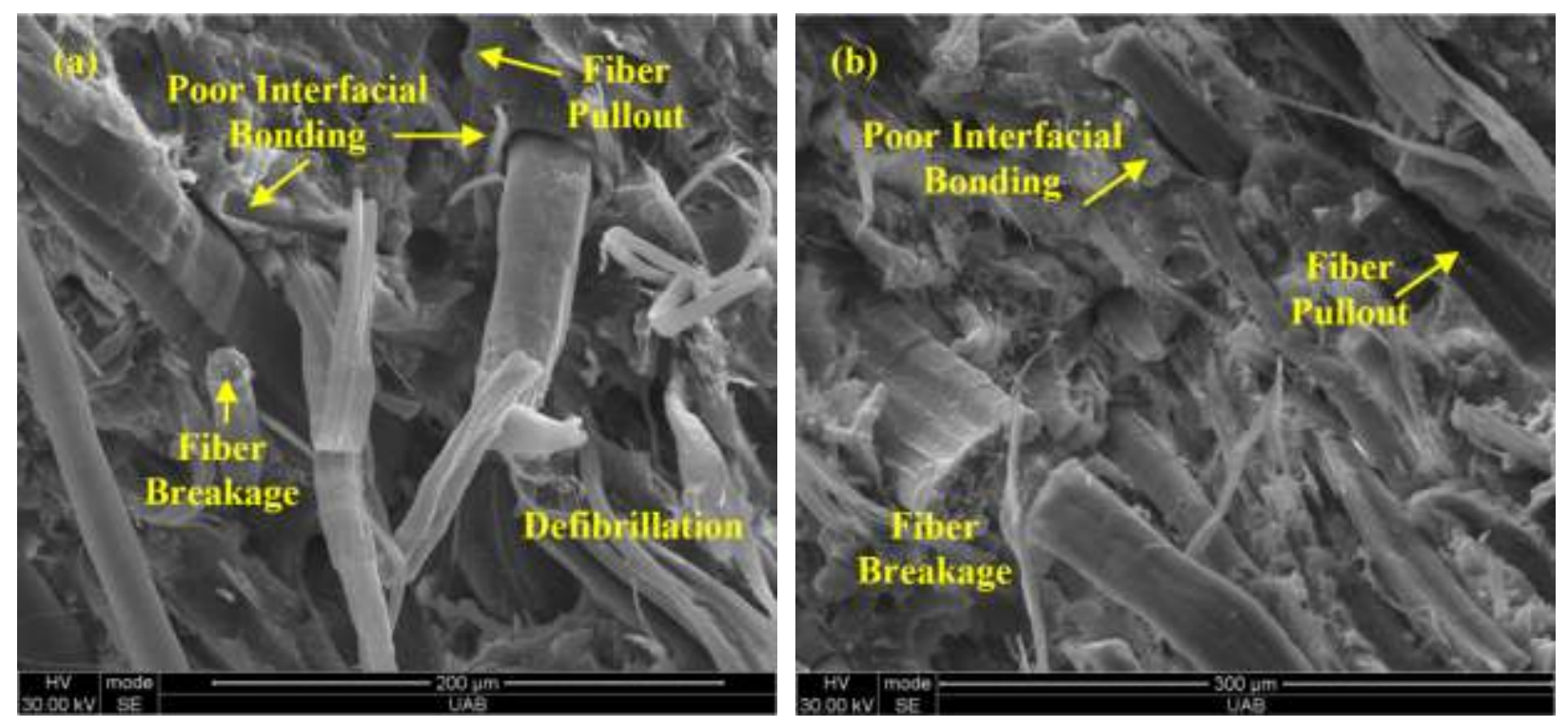


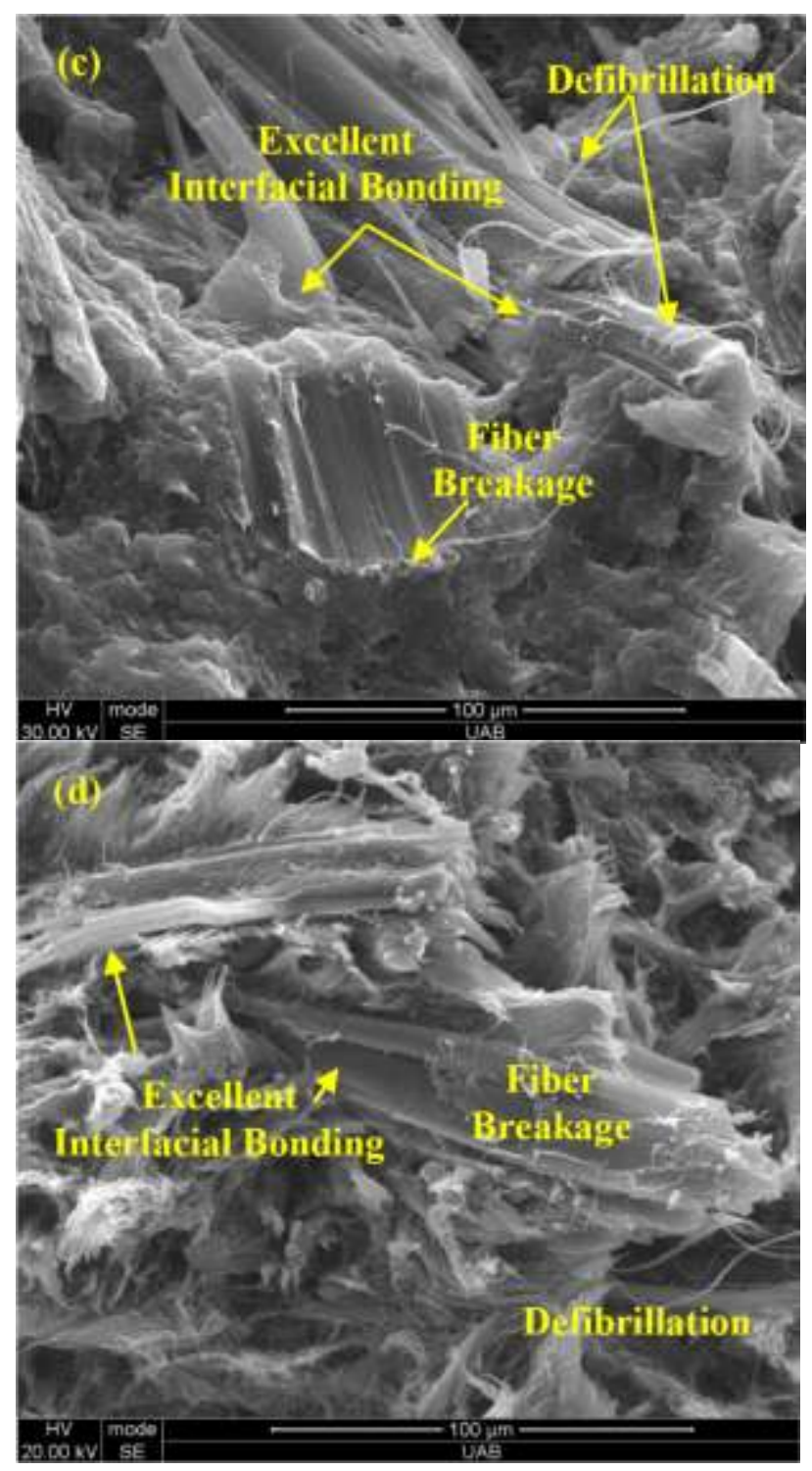

Figure 15. SEM images of $30 \mathrm{wt} \%$ hemp fiber reinforced PP composite fiber fracture surfaces of (a) 30-UT, (b) 30-5NaOH, (c) 30-5MAPP and (d) 30-5NaOH-5MAPP. 